\title{
BMJ Open Development of a patient safety culture scale for maternal and child health institutions in China: a cross-sectional validation study
}

Yuanyuan Wang, ${ }^{1}$ Hui Han, ${ }^{2}$ Liqian Qiu, ${ }^{3}$ Chaojie Liu, ${ }^{4}$ Yan Wang, ${ }^{2}$ Weiwei $\mathrm{Liu}^{5}$

To cite: Wang Y, Han H, Qiu L, et al. Development of a patient safety culture scale for maternal and child health institutions in China: a cross-sectional validation study. BMJ Open 2019:9:e025607. doi:10.1136/ bmjopen-2018-025607

- Prepublication history and additional material for this paper are available online. To view these files, please visit the journal online (http://dx.doi. org/10.1136/bmjopen-2018025607).

YW and WL contributed equally.

Received 25 July 2018

Revised 22 May 2019

Accepted 15 July 2019

\section{Check for updates}

(c) Author(s) (or their employer(s)) 2019. Re-use permitted under CC BY-NC. No commercial re-use. See rights and permissions. Published by BMJ.

For numbered affiliations see end of article.

\section{Correspondence to} Professor Weiwei Liu; vivian_liu@bjmu.edu.cn

Professor Yan Wang; wangyan@bjmu.edu.cn

\section{ABSTRACT}

Objective This study aimed to develop a patient safety culture (PSC) scale for maternal and child healthcare (MCH) institutions in China.

Methods A theoretical framework of PSC for $\mathrm{MCH}$ institutions was proposed through in-depth interviews with MCH workers and patients and Delphi expert consultations. The reliability and validity of the PSC scale were tested in a cross-sectional survey of $1256 \mathrm{MCH}$ workers from 14 MCH institutions in Zhejiang province of China. The study sample was randomly split into half for exploratory and confirmatory factor analyses, respectively. Test-retest reliability was assessed through a repeated survey of 63 voluntary participants 2 weeks apart.

Results The exploratory factor analysis extracted 10 components: patient engagement in patient safety (six items), managerial response to patient safety risks (four items), perceived management support (five items), staff empowerment (four items), staffing and workloads (four items), reporting of adverse events (three items), defensive medical practice (three items), work commitment (three items), training (two items) and transfer and handoff (three items). A good model fit was found in the confirmatory factor analysis: $\chi^{2}$ / $\mathrm{df}=1.822$, standardised root mean residual $=0.048$, root mean square error of approximation $=0.038$, comparative fit index $=0.921$, Tucker-Lewis index $=0.907$. The PSC scale had a Cronbach's $\alpha$ coefficient of 0.89 (0.59-0.90 for dimensional scales) and a test-retest reliability of 0.81 (0.63-0.87 for dimensional reliability), respectively. The intracluster correlation coefficients confirmed a hierarchical nature of the data: individual health workers nested within $\mathrm{MCH}$ institutions.

Conclusion The PSC scale for MCH institutions has acceptable reliability and validity. Further studies are needed to establish benchmarking in a national representative sample through a multilevel modelling approach.

\section{INTRODUCTION}

The burden of unsafe healthcare is overwhelming, ${ }^{1-3}$ resulting in increasing attention all over the world. ${ }^{4-7}$ One of the most salient challenges for building a safer healthcare system is to develop a just culture,${ }^{89}$ in which common values, beliefs, attitudes, norms
Strengths and limitations of this study

- Through a multi-stage research progress of quantitative and qualitative methods, a patient safety culture (PSC) scale for maternal and child healthcare (MCH) institutions was developed and verified on the basis of views and responses from different stakeholders, including front-line staff, managers, patients and experts in relevant fields.

- A hierarchical nature of PSC within MCH institutions in China has been preliminarily explored by intracluster correlation coefficients and design effects.

- Like most PSC tools, the PSC scale for MCH institutions collects data based on subjective reporting, in the absence of observable indicators.

- The results are context specific and caution should be taken when generalising the results.

and behavioural characteristics on patient safety are shared by members of an organisation. ${ }^{1011}$ This is often called patient safety culture (PSC) or patient safety climate. A good PSC leads to good attitudes and behaviours of health workers, better patient care outcomes and more resilient organisations. ${ }^{12-18}$

It is important to measure PSC before any targeted intervention strategies are developed. ${ }^{11} 19$ PSC can be observed through a range of organisational behaviours, such as leadership, communication, teamwork, error reporting, non-punitive approach to errors, continuous learning and evidencebased practice and so on. ${ }^{20}$ There have been a number of PSC measurement tools widely used around the world, such as the Hospital Survey on Patient Safety Culture (HSPSC), ${ }^{22}$ the Patient Safety Climate in Healthcare Organizations (PSCHO),${ }^{23}$ the Safety Attitudes Questionnaire, ${ }^{24}$ and the Manchester Patient Safety Assessment Framework. ${ }^{25}$ Several PSC tools have also been made available in China. ${ }^{26-31}$ However, there is a consensus that PSC measurements need 
to adapt to the contexts of services, institutions, units and even individuals. ${ }^{32-36}$

Maternal and child healthcare (MCH) is one of the most important concerns in the sustainable development goals. ${ }^{37} \mathrm{MCH}$ services refer to care for children during growth and development period and care for women during pregnancy, childbirth and postpartum period. Such services involve not only medical interventions on illness conditions, but also health promotion activities and preventive care. Integration of these services is essential to ensure optimal care outcomes, which often involves multiple providers and cross-organisational collaborations. Unfortunately, MCH consumers (women and children) are usually disadvantaged in access to healthcare due to their relatively low socioeconomic status. ${ }^{38} 39$ China has $3078 \mathrm{MCH}$ institutions, with the majority $(99.7 \%)$ owned by the government. ${ }^{40}$ The comprehensive network of $\mathrm{MCH}$ institutions covers all geographic catchments at the provincial, municipal and county levels. ${ }^{41}$ Besides providing $\mathrm{MCH}$ services, MCH institutions are considered part of the public health management system in China, taking a leading role in $\mathrm{MCH}$ care associated matters such as MCH statistics, workforce development and service supervisions. This network is believed to have played a critical role in China's remarkable achievements on reducing under-five mortality rate and maternal mortality ratio ${ }^{42}$ and China has been evaluated by WHO as one of 10 low-income and middle-income 'fast-track' countries for $\mathrm{MCH}^{43}$ As China has increasingly participated in global health governance, China's model and experiences in $\mathrm{MCH}$ has been introduced into many low-income and middle-income countries. ${ }^{44-46}$

There is a paucity in the literature measuring PSC in $\mathrm{MCH}$ care settings, except for some studies in MCH clinical services. ${ }^{47} 48$ The existing PSC tools, which mainly focus on hospital services, may not be applicable to $\mathrm{MCH}$ settings due to the special nature of MCH services, especially for those public health services. ${ }^{49}$ Thus, this study aimed to develop a PSC scale tailored to the specific context of MCH institutions in China. This scale can be used to measure PSC in MCH care settings and helpful to develop other PSC tools for public health services.

\section{METHODS}

\section{Theoretical framework development}

A theoretical framework was developed for conceptualising PSC through in-depth interviews (November 2014April 2015) with $79 \mathrm{MCH}$ workers (20 managers, 59 care providers) and 39 patients from six MCH institutions (three in Hebei province and three in Beijing). A PSC framework emerged as a result of both inductive (based on the existing PSC theories) and deductive (open coding arising from data ${ }^{50}$ ) coding, containing 12 components and 69 items. Findings of the in-depth interviews and informed consent statement were published elsewhere. ${ }^{51}$

The content validity of the framework was evaluated through Delphi expert consultations. Fifteen experts (in the areas of MCH, patient safety, health services management, nursing management and evidence-based medicine) were invited to participate in three-round mail/ email consultations (from September to November 2015). This resulted in a consensus of a 12-component framework, comprising 67 items: 30 items were modified to avoid ambiguity; three were moved from their prior assigned components to new ones; six items were rephrased into three; one item was deemed irrelevant and removed; two new items were added.

\section{Item reduction}

The theoretical framework was transformed into a questionnaire (the PSC survey for maternal and child health institutions, PSC scale for MCH institutions (PSCS-MCHI) (V.1.0)), with each item being rated on a 5-point Likert scale: $1=$ =strongly disagree, $2=$ disagree, $3=$ =neither, $4=$ agree, $5=$ strongly agree. Two additional items were added in line with the HSPSC developed by the Agency for Healthcare Research and Quality, ${ }^{22} 52$ measuring 'overall grade of patient safety' ( $5=$ excellent, $4=$ very good, $3=$ acceptable, $2=$ poor, $1=$ failing) and 'number of events reported in the last 12 months' ( $1=$ no events, $2=1$ to 2 events, $3=3$ to 5 events, $4=6$ to 10 events, $5=11$ to 20 events, $6=21$ events or more), respectively.

In January 2016, we invited 61 health workers from three $\mathrm{MCH}$ institutions in Beijing to participate in six focus groups (7-12 participants with different backgrounds for each group, two groups per institution). They completed the questionnaire first and then offered recommendations for improving the questionnaire. On average, the participants spent $12 \mathrm{~min}$ to complete the questionnaire (including the sociodemographic questions). As a result of the focus groups, wording of several questions was modified, along with a more detailed instruction for completion (PSCS-MCHI (V.2.0)).

In January and February 2016, a pilot survey was conducted on $429 \mathrm{MCH}$ workers (including 46 repeated survey 2 weeks apart, according to approximately $10 \%$ sampling design in each institution and the principle of voluntary participation) from the same three MCH institutions in Beijing. Both classical test theory and item response theory ${ }^{53}$ were applied in data analyses: 21 items were filtered out, resulting in a 46-item scale (PSCS-MCHI (version 3.0)).

\section{Validation study}

The validation study was conducted in Zhejiang province from October 2016 to January 2017. Zhejiang has $88 \mathrm{MCH}$ institutions. ${ }^{40} \mathrm{~A}$ call for expression of interest resulted in $14 \mathrm{MCH}$ institutions participating in the study, including all levels of MCH institutions: one provincial hospital, three municipal hospital, one county-level hospital and nine county-level centre (online supplementary appendix A shows the characteristics of the participating institutions).

All MCH workers from the participating institutions were eligible for this study, including managers, medical 
doctors, nurses, midwives, public health workers, allied health workers, pharmacists and support workers (eg, IT technicians, administrative staff, security workers and cleaners). They were invited to self-complete the survey anonymously on a voluntary based. A total of 1329 questionnaires were dispatched (along with an informed consent statement, return of the questionnaire was deemed consent, which was completely voluntary and anonymous), representing $22 \%$ of the eligible participants. The participants were requested to return their completed questionnaires within 2 weeks to a deposit box placed in their institutions. All returned questionnaires with at least $80 \%$ of completed items (37 out of 46 items) were deemed valid and included in data analyses. This resulted in a final sample size of 1256 (91\% of returned questionnaires). Of the participants, 70 volunteered to repeat the survey 10-14 days after completion of the initial survey: 63 (90\%) returned a valid questionnaire in the repeated survey. This study's ethical approval was obtained from Peking University Third Hospital Medical Science Research Ethics Committee (IRB00006761-M2014040).

\section{Patients and public involvement}

Patients and the public were not directly involved in the design and conception of this study.

\section{Statistical analysis}

The 46 items measuring PSC contained 15 negatively worded items. They were all coded in a consistent way, with one indicating the worst PSC and five indicating the best PSC. Item scores in the same component were summed up to generate a composite score. As most exiting PSC tools, the data of scores in this study are not weighted yet. The questionnaire also collected socio-demographic information of the respondents (eg, age, sex, educational attainment, years of working in health industry, years of working with current employer, position, average weekly workload and direct contacts with patients). The distribution of respondents with different characteristics was compared between the two samples split for factor analyses (see details below) and against the total sample.

The sample was randomly split into half for exploratory factor analysis (EFA, n=628) and confirmatory factor analysis (CFA, $n=628$ ), respectively. The EFA extracted a structure of the scale, which was then confirmed in the CFA. We used principal axis factoring with varimax rotation in EFA. The number of extracted factors was determined by eigenvalues $(\lambda>1)$. An item with a lower than 0.4 factor loading score on any extracted factors or with serious cross-loadings (similar loadings on two or more factors) was removed. ${ }^{285}$ We performed CFA with robust maximum likelihood because the distribution of data was not normal..$^{55}$ The fitness of model was examined using a series of indices: chi-square $/ \mathrm{df}\left(\chi^{2} / \mathrm{df}<3\right)$, standardised root mean residual (SRMR $<0.05$ ), root mean square error of approximation (root mean square error of approximation (RMSEA) <0.05), comparative fit index
$(\mathrm{CFI}>0.90)$, and Tucker-Lewis index $(\mathrm{TLI}>0.90) .{ }^{56-58}$ In addition, the factor loading scores have to exceed 0.40 .

The total sample was then used for further examinations of the reliability of the confirmed scale, and the hierarchical nature of the PSC data. The subscales (components) of the PSC scale were supposed to be correlated but with a $<0.80$ correlation coefficient to be considered unique and free from multicollinearity. ${ }^{52}$ We used Spearman rank-order correlation tests because the distribution of data was not normal (online supplementary appendix 1). We calculated Cronbach's alpha $(\alpha)$ coefficients to assess the internal consistency of the PSC scale and its subscales. The test-retest reliability was assessed using Spearman rank-order correlation coefficients (for non-normal distributed data). A Cronbach's $\alpha$ or a Spearman correlation coefficient over 0.70 was considered an indication of good reliability. ${ }^{11}$

We assumed that the PSC data had a hierarchical structure: individual health workers nested within $\mathrm{MCH}$ institutions. To test the hypothesis, we calculated intracluster correlation coefficients (ICCs) to assess both within-level homogeneity and between-level heterogeneity. ${ }^{59}$ The ICCs for each subscale were estimated as a ratio of between-level variance $\left(\sigma^{2}{ }_{w}\right)$ to total variance $\left(\sigma_{b}^{2}\right)$ using an empty model (which is identical to a one-way random effect analysis of variance): ICC $=\sigma_{b}^{2} /\left(\sigma_{w}^{2}+\sigma_{b}^{2}\right){ }^{60}$ A high ICC value $(>0.05)$ indicates that multilevel modelling should be considered for explaining between-level heterogeneity. ${ }^{28}{ }^{52}$ But because ICG values are sensitive to the within-level sample size, we calculated design effects, which equal to $1+$ (average within level sample size-1)*ICC. The multilevel nature of data should be assumed when the design effect is higher than $2 .{ }^{52} 61$ In this study, we tested three sets of two-level models: individualposition (individuals clustered by position); individual-institution (individuals clustered by institution); individual-(position*institution) (individuals clustered by position and institution). In order to reach the least within-level sample size $(\geq 10),{ }^{60}$ only 36 groups with 10 or more individuals in each group (up to 985 individuals in total) were included in the individual-(position*institution) analysis.

We used Epidata V.3.1 software for data entry, Mplus V.5.1 software for CFA, and SPSS V.20.0 software for all other analyses.

\section{RESULTS}

\section{Characteristics of respondents}

Most respondents (87\%) were female; about half were younger than 35 years old; $72 \%$ obtained a university degree. The largest group of respondents was medical doctors (29\%), followed by nurses and midwives (28\%), allied health (13\%) and public health workers (12\%). No significant differences were found in the characteristics of respondents between the samples for EFA and CFA (table 1). 
Open access

Table 1 Characteristics of respondents (\%)

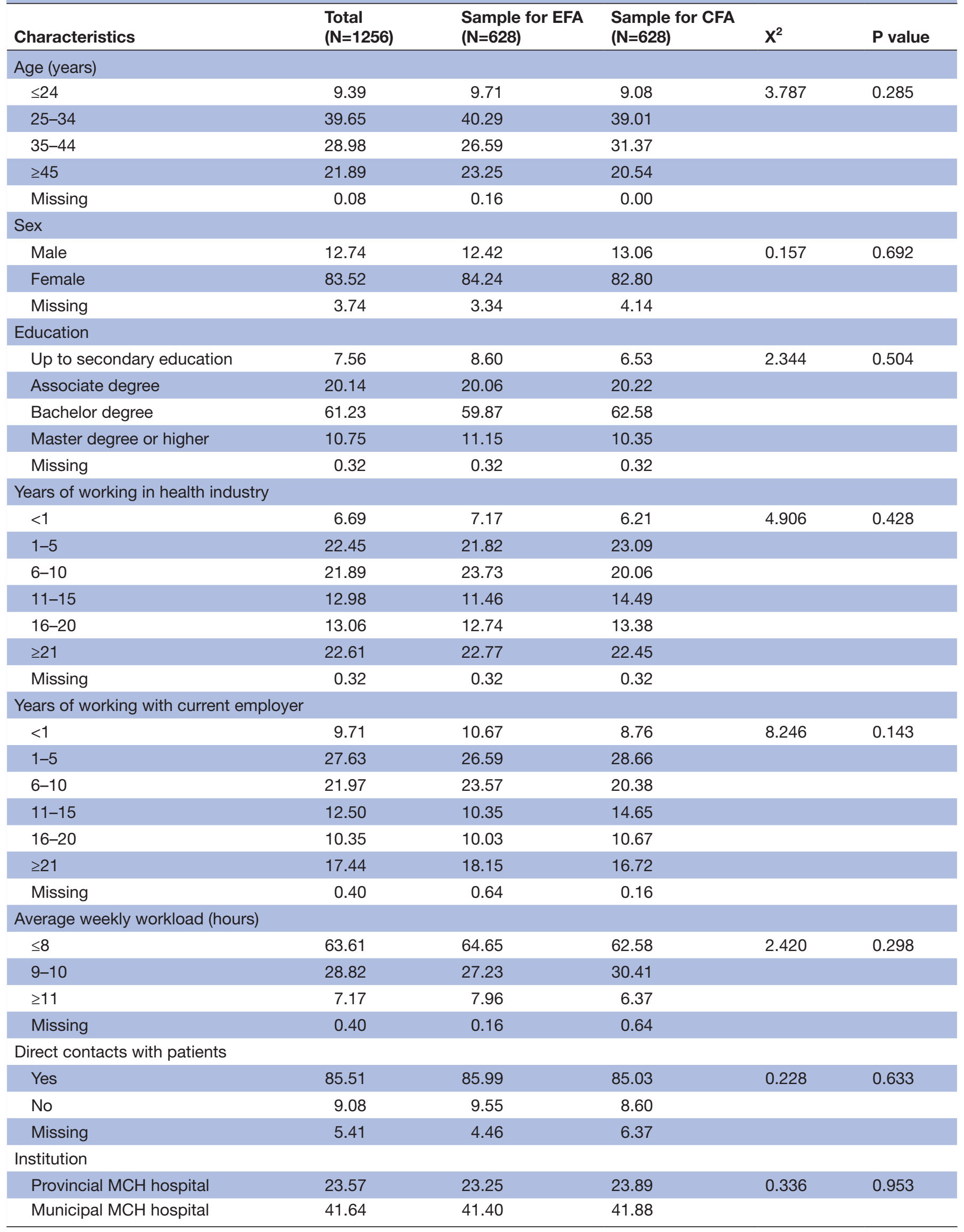

Continued 


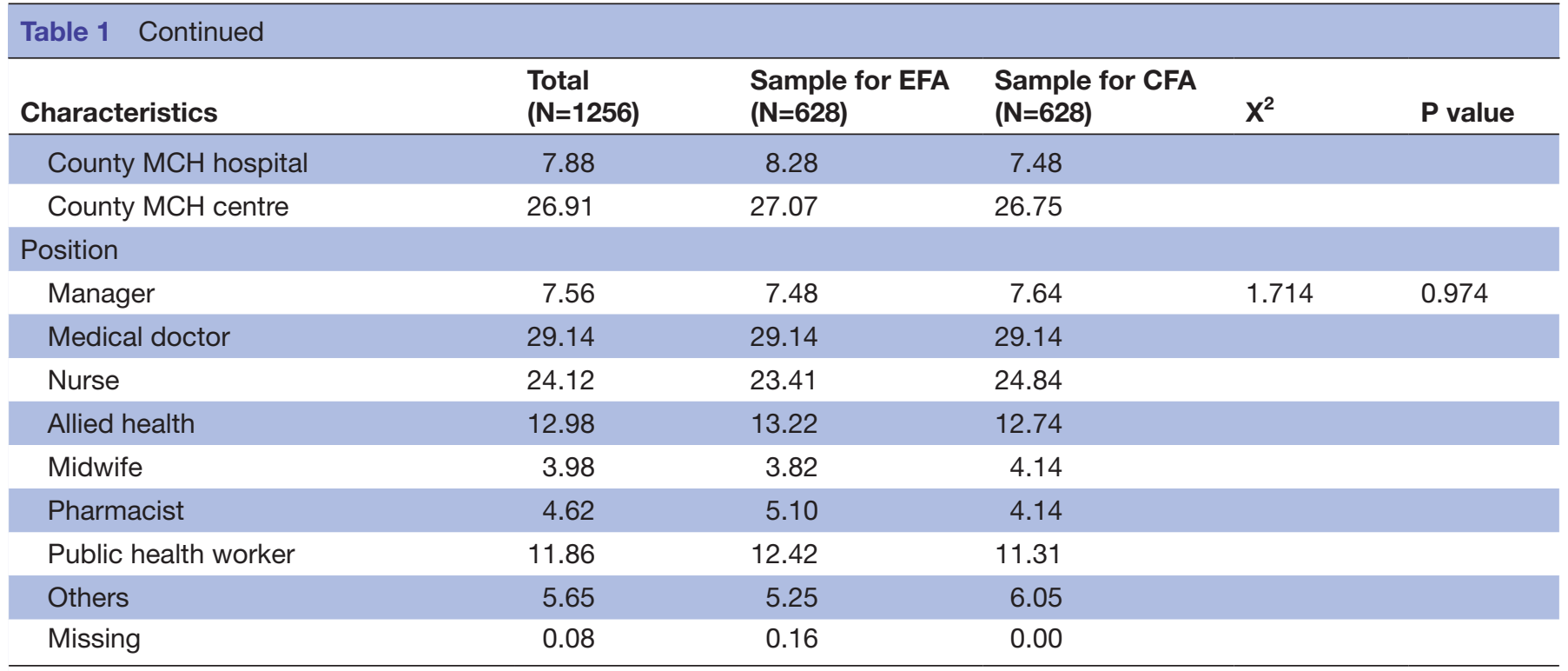

Percentages may not add to 100 due to rounding.

CFA, confirmatory factor analysis; $\mathrm{EFA}$, exploratory factor analysis; $\mathrm{MCH}$, maternal and child healthcare.

\section{Construct validity of the PSC scale}

The EFA resulted in a scale with 10 components and a total of 37 items (table 2). Nine items were removed: four items (Q92, Q56, Q43 and Q46) were removed due to low factor loadings $(\leq 0.40)$; three $(\mathrm{Q} 21, \mathrm{Q} 81$ and Q114) were removed due to serious cross-loadings; one (Q53) was removed because it was the sole item for an additional factor (factor 11). In addition, another item (Q72) was removed because it loaded high on a factor (Factor 1) deviated from its prior assigned component.

The 10 components were named as: (1) patient engagement (six items); (2) managerial response to patient safety risks (four items); (3) perceived management support (five items); (4) staff empowerment (four items); (5) staffing and workloads (four items); (6) reporting of adverse events (three items); (7) defensive medical practice (three items); (8) work commitment (three items); (9) training (two items); (10) transfer and handoff (three items). The CFA confirmed that the 10-component structure of PSC scale (37 items) had a good model fit: $\chi^{2}=1040.263, \mathrm{df}=571, \mathrm{p}<0.001, \chi^{2} / \mathrm{df}=1.822, \mathrm{SRMR}=0.048$, RMSEA $=0.038$ (90\% CI 0.034 to 0.041$)$, CFI $=0.921$, TLI $=0.907$. All of the 37 items had a factor loading exceeding 0.4 (table 2).

\section{PSC scores and correlations}

The mean item scores ranged from 2.18 to 4.16 , with a ceiling effect (percentage of respondents with the maximum score) ranging from $0.48 \%$ to $23.81 \%$ and a floor effect (percentage of respondents with the minimum score) ranging from $0 \%$ to $20.78 \%$. The respondents had a mean subscale score ranging from 2.37 ('staffing and workloads') to 4.02 ('work commitment'). Ceiling effects and floor effects on subscale scores were found in $0.16 \%-5.10 \%$ and $0 \%-2.23 \%$ of respondents, respectively (details can be found in online supplementary appendix B).

The subscales had weak to medium positive correlations $(p<0.001)$, except for the component of 'staffing and workloads' (table 3). 'Staffing and workloads' was found to be negatively correlated with 'reporting of adverse events' and 'work commitment' $(\mathrm{p}<0.05)$. It had no significant correlations $(p>0.05)$ with 'patient engagement', 'managerial response to patient safety risks' and 'transfer and handoff'.

Overall, the respondents gave a positive rating to patient safety: $16.64 \%$ 'excellent', $54.58 \%$ 'very good' and $27.45 \%$ 'acceptable', compared with $1.16 \%$ 'poor' and $0.17 \%$ 'failing'. The majority $(78.59 \%)$ did not report any events over the past 12 months, while $18.47 \%$ reported $1-2$ events, $2.85 \%$ reported $3-5$ events and $0.08 \%$ reported 6-10 events. Patient safety grade was correlated with all of the 10 PSC subscales $(\mathrm{p}<0.001)$. Whereas, the number of events reported was only correlated with 'reporting of adverse events' and 'work commitment' $(p<0.05)$.

\section{Reliability of the PSC scale}

The PSC scale had a Cronbach's $\alpha$ coefficient of 0.89 , with seven dimensional $\alpha$ exceeding 0.70 . Three subscales had lower than $0.7 \alpha$ coefficients: 0.591 for 'defensive medical practice' (increased to 0.645 if Q12 was removed); 0.690 for 'staffing and workloads' (increased to 0.715 if Q36 was removed); 0.657 for 'transfer and handoff' (increased to 0.731 if Q45 was removed). Further analyses revealed negligible impacts on the validity of the PSC scale by removing Q12, Q36 and Q45 (online supplementary appendix C-E). The test-retest reliability of the PSC reached 0.81 , with eight subscales exceeding 0.7 and two exceeding 0.6 (table 3 ). 


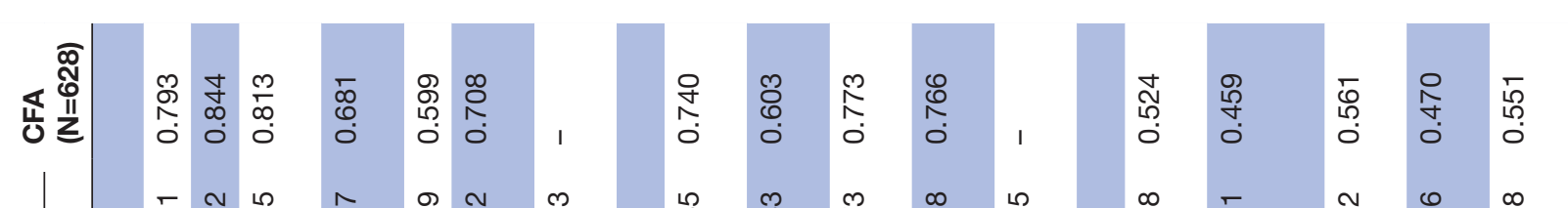

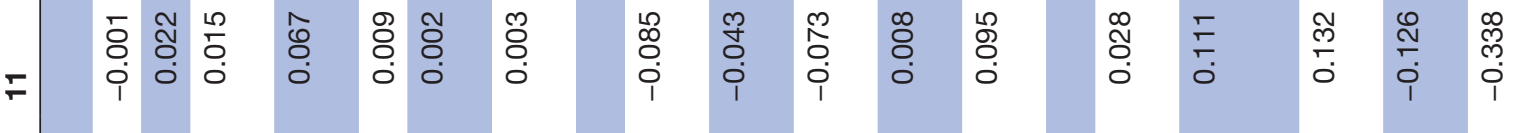

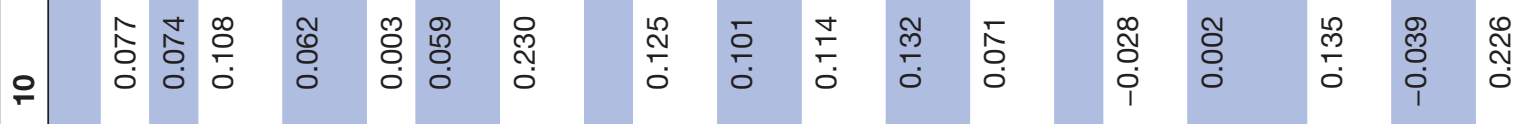

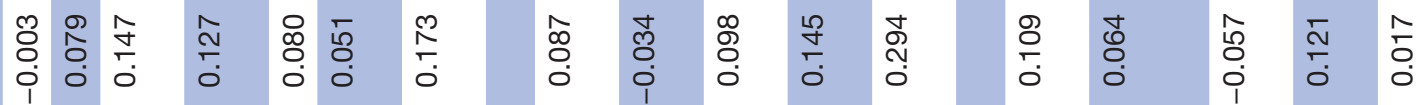

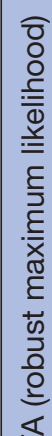

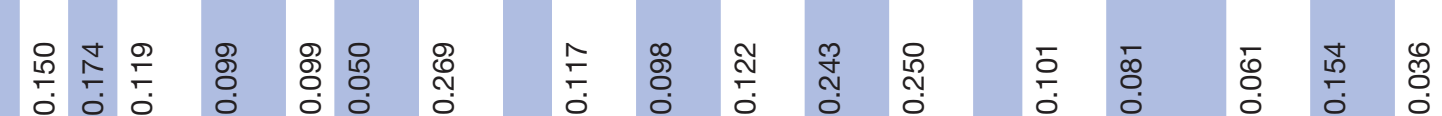

బิ้

$\checkmark$.

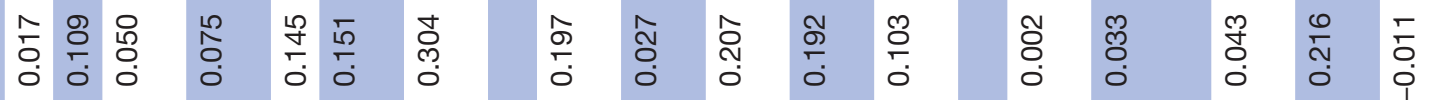

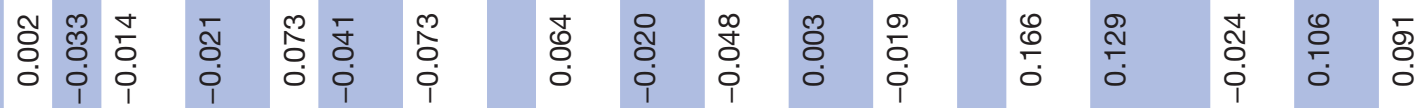

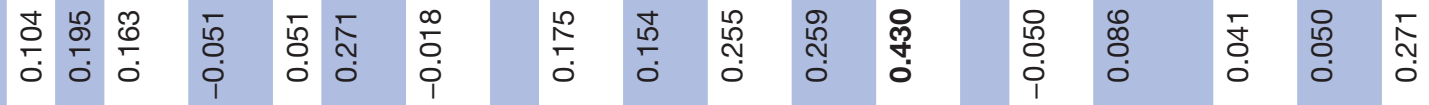

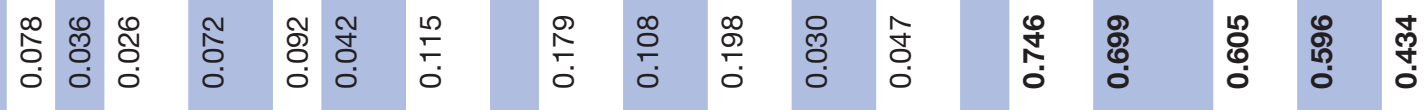

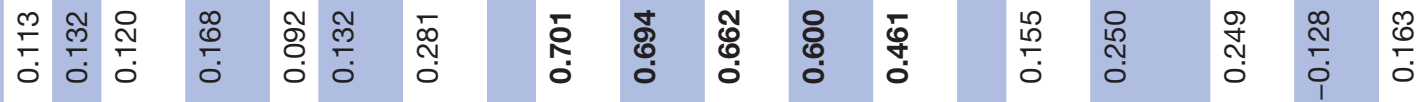

ণิֻ

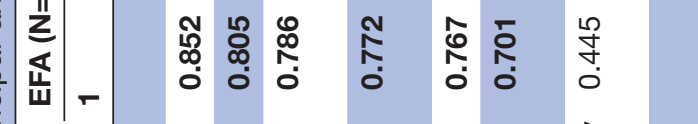

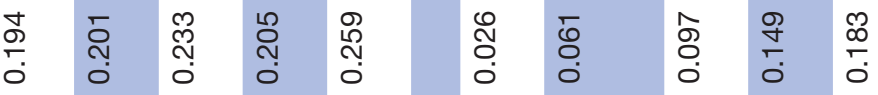

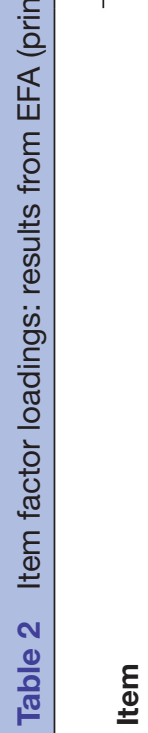

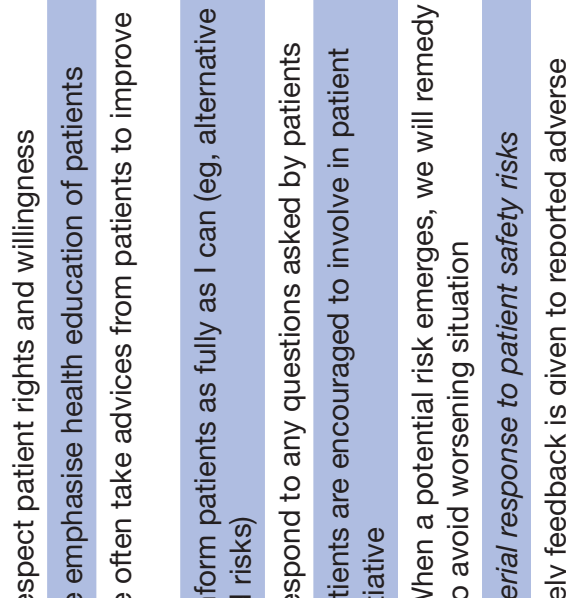

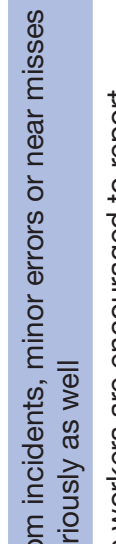

물

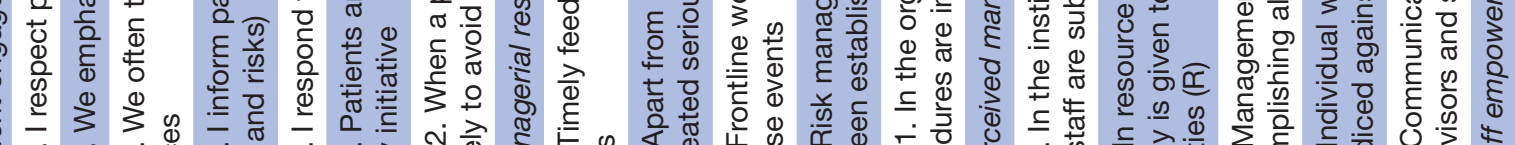

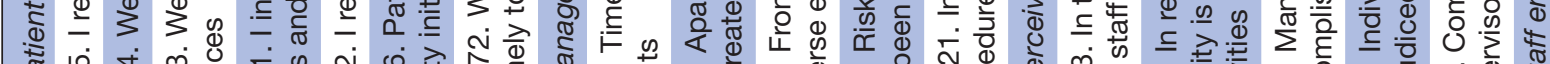

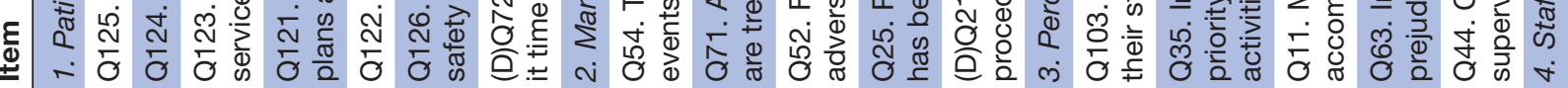




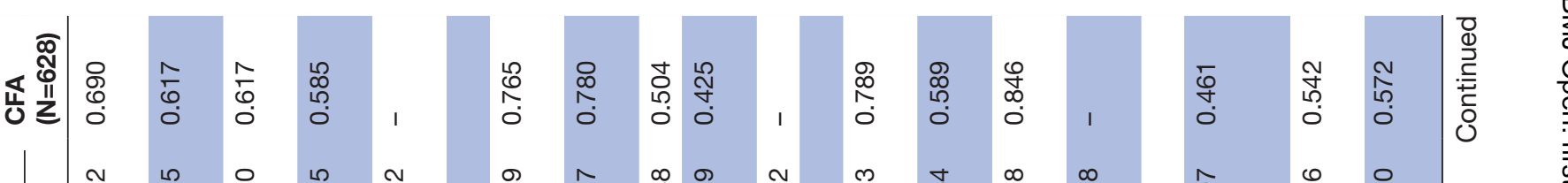

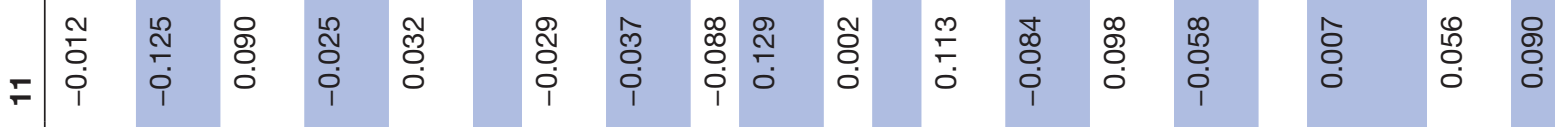

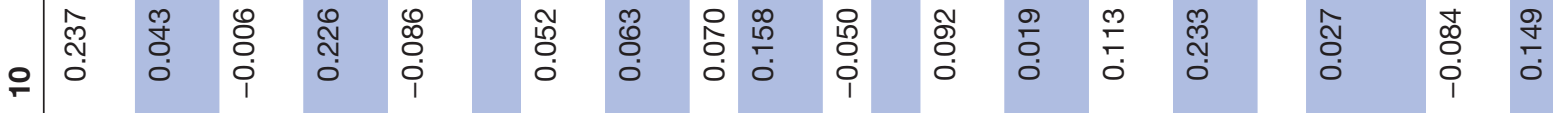
๑

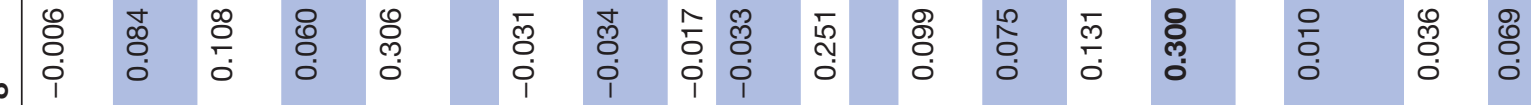

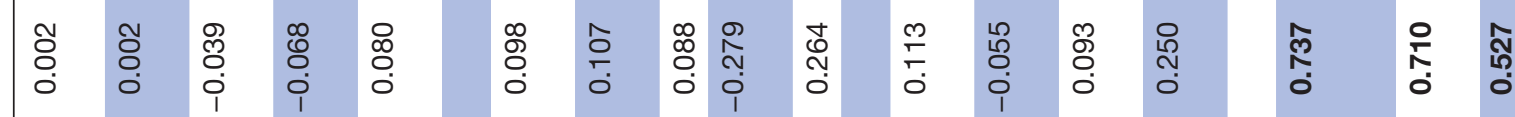

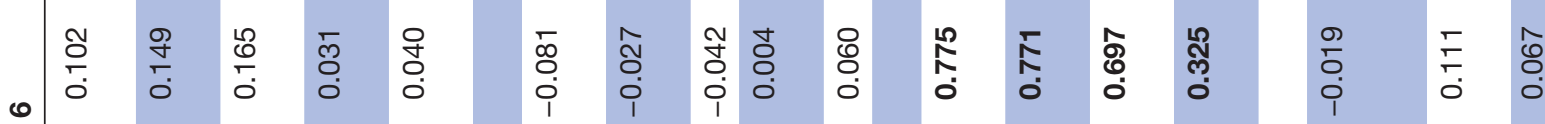

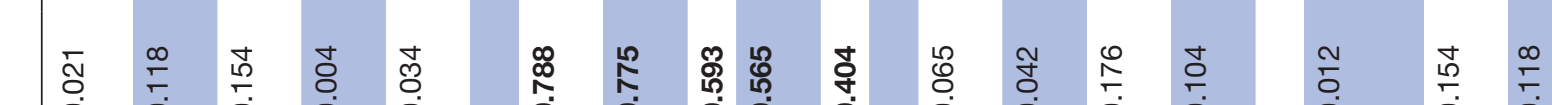

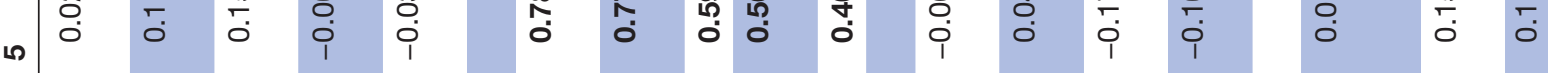

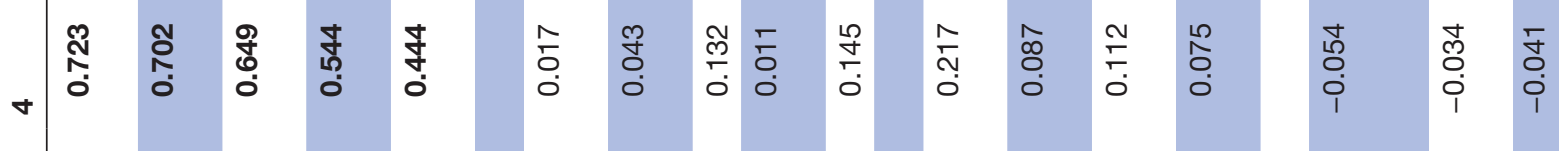

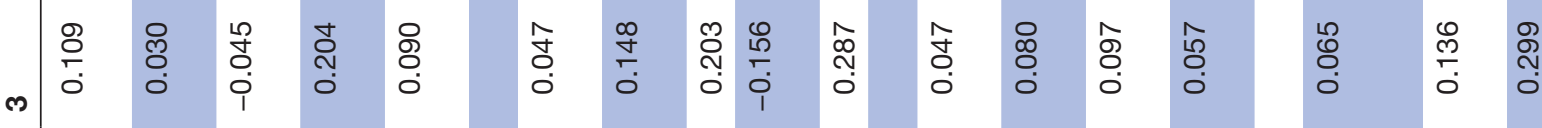

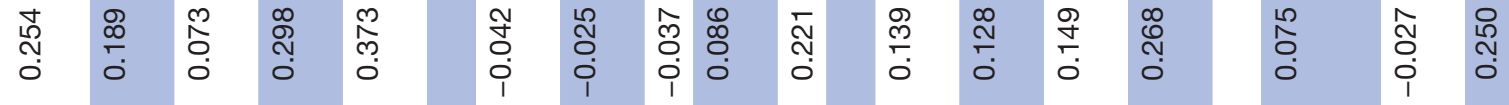

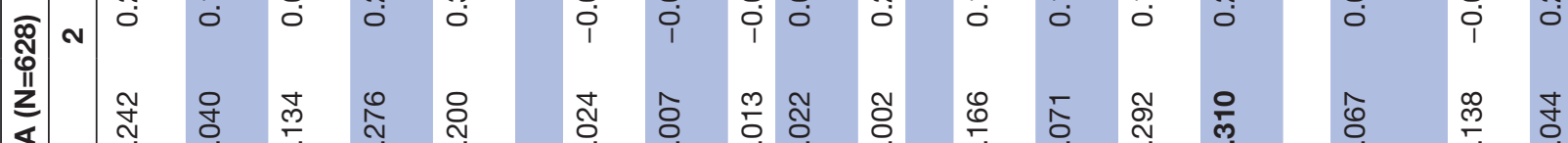

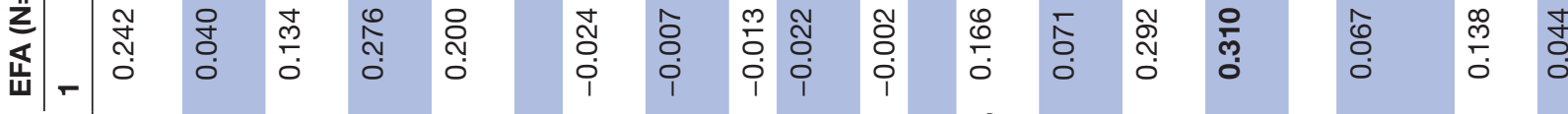

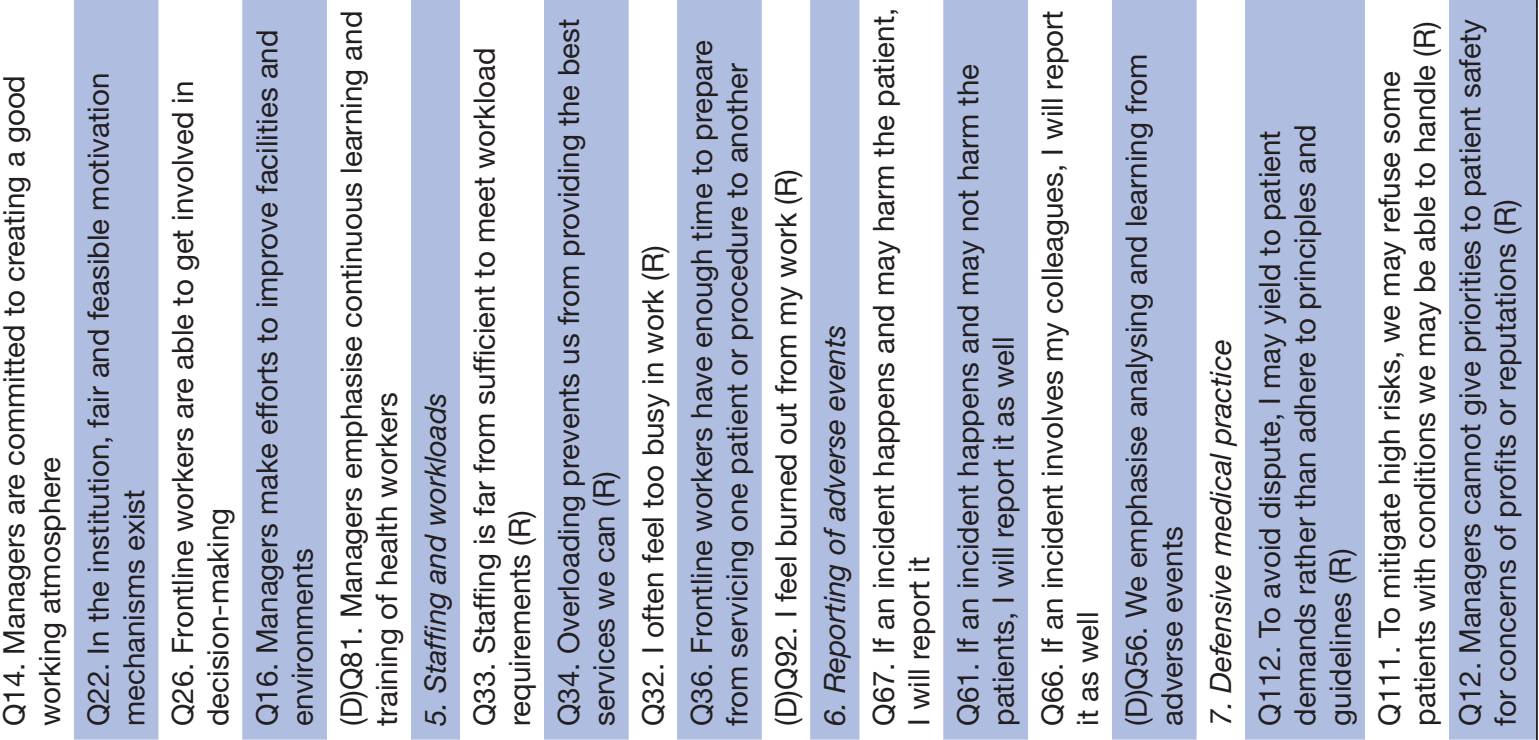




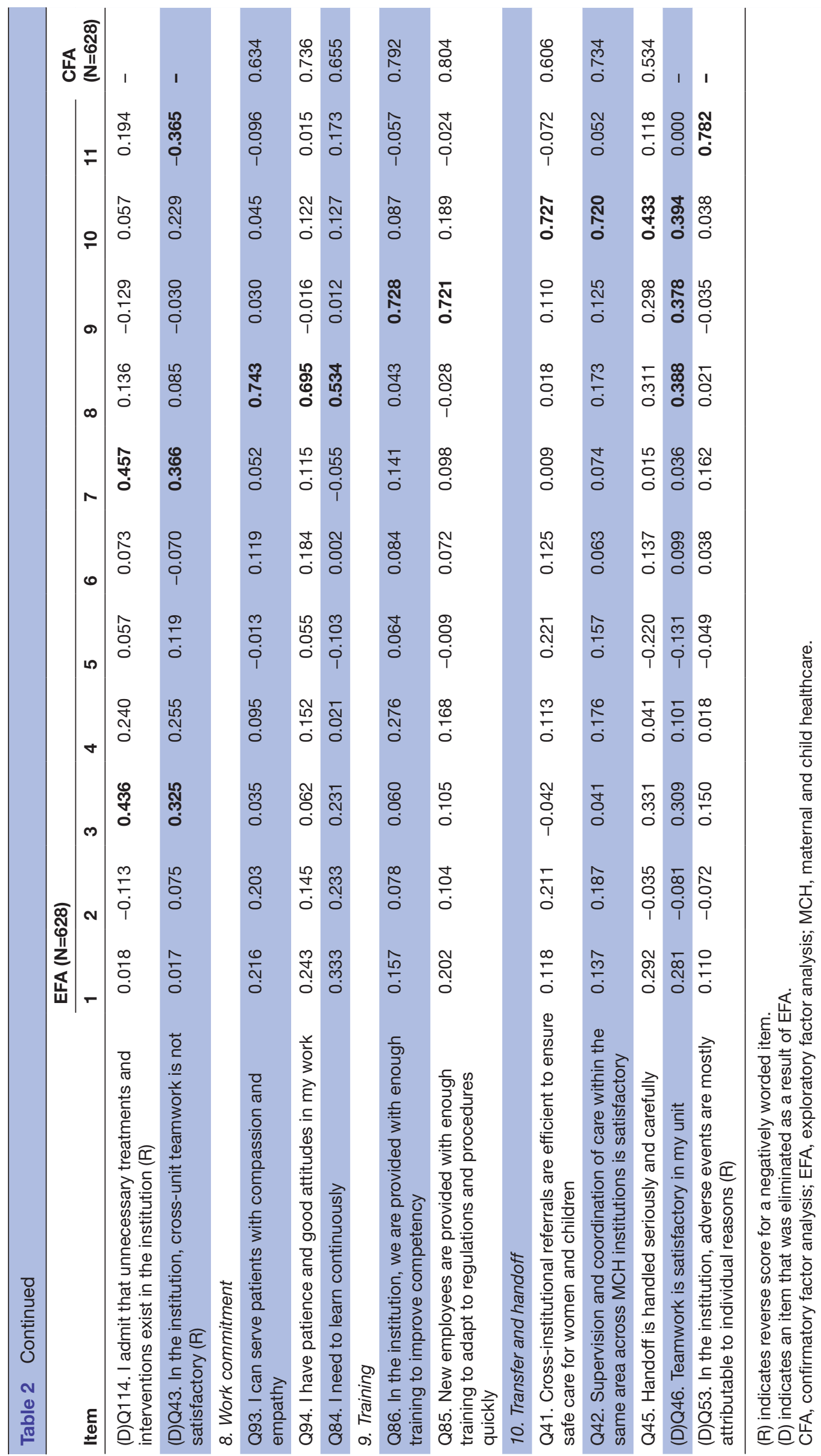




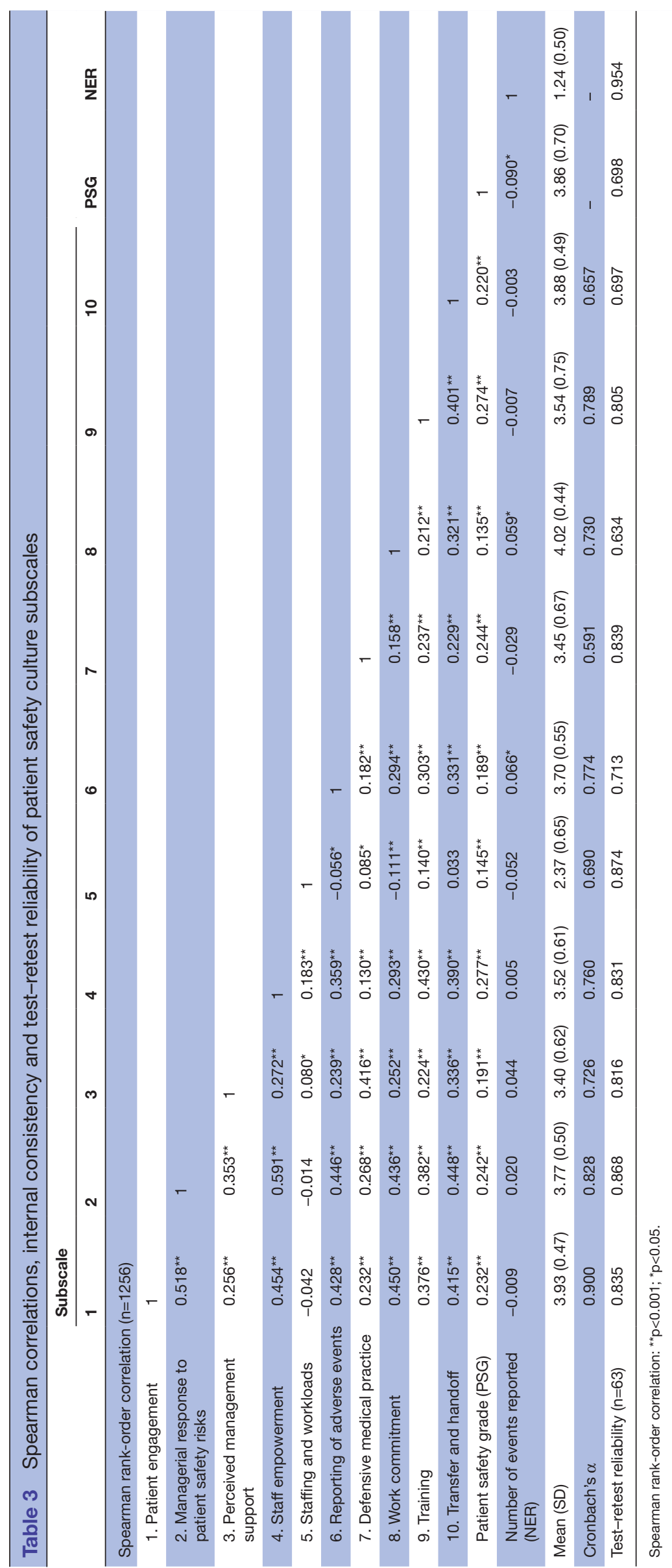

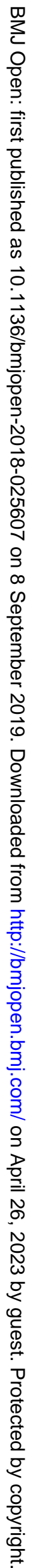




\section{ICCs and design effects}

Low ICC values were observed, possibly as a result of large within-cluster sample size. In this study, we had an average of 157 individuals per position and 90 individuals per institution. Only two subscales in the individual-position analyses, three subscales in the individual-institution analyses and seven subscales in the individual-'position $\times$ institution' analyses generated an ICC value greater than 0.05 (table 4).

The design effects (adjusted by the number of individuals within a cluster) revealed eight subscales in the individual-position analyses, seven subscales in the individual-institution analyses and nine subscales in the individual-'position*institution' analyses exceeding the threshold of 2.00 (table 4). The design effects of 'patient safety grade' and 'number of events reported' also exceeded 2.00 in all of the three sets of ICC analyses (further details on ICCs and design effects can be found in online supplementary appendix F).

Individuals clustered by (position*institution): 985 individuals (level 1) nested within 36 (position*institution) groups (level 2), excluding 62 groups with less than 10 individual compositions.

\section{DISCUSSION}

\section{Components of PSCS-MCHI}

This study developed a PSCS-MCHI, comprising 10 subscales measured by 37 items. The PSCS-MCHI is tailored to the special context of MCH institutions in China. Its compositions share some common themes captured in the existing tools measuring PSC. For example, 'managerial response to patient safety risks', 'perceived management support', 'staffing and workloads', 'reporting of adverse events', 'training' and 'transfer and handoff' have been featured in the HSPSC and the PSCHO. ${ }^{22} 23$ However, there are also several themes that are particularly highlighted in the PSCS-MCHI, including 'defensive medical practice', 'work commitment', 'patient engagement' and 'staff empowerment'. Questions in relation to these themes may appear in other PSC tools, but most are not treated as a separate subscale.

The underlined reasons behind the emergence of these new subscales have to be traced back from the special contexts of MCH services in China. China has experienced unprecedented economic growth over the past few decades, accompanied by considerable advancement in medical technologies. This has stimulated very high consumer expectations on quality of healthcare. Such high expectations are further compounded by the one-child family planning policy adopted in China since late 1970s (although the government has recently relaxed this policy by allowing two children for each family). However, medical care outcomes often fall short of expectations. The contradiction between reality and expectations often leads to consumer distrust in medical practice, which has been further exacerbated by soaring financial burdens of medical care. ${ }^{62}$ Consequently, defensive medical practice, in particular over-provision of service, has become a growing concern from the consumer perspective. Consumers demand increasing power in clinical decision making. Meanwhile, health workers also want consumers to be more accountable to their own healthcare. This is particularly important for MCH care, which requires consumers to comply with a plan involving continuing and coordinated services across a long period of time. Although patients have enjoyed a high level of freedom in choosing care providers in China, clinical autonomy of health workers has been subject to increasing restrictions due to policy and managerial interventions. It is important to note that health workers, including medical practitioners, are usually salaried fulltime employees of health organisations in China. Empirical evidence shows that a lack of participation of health workers in management decisions may jeopardise patient care outcomes. ${ }^{63}$ Understandably, 'staff empowerment' and 'work commitment' are valued by health workers as important elements of PSC.

\section{Psychometric properties of PSCS-MCHI}

The PSCS-MCHI (37 items) has acceptable reliability and validity. The scale was developed through a rigorous process, involving in-depth interviews, expert consultations, focus groups, and quantitative psychometric testing (figure 1). The 10 component structure of the PSCS-MCHI extracted by the EFA is confirmed by the CFA. The scale has demonstrated acceptable internal consistency and test-retest reliability. The hierarchical nature of the PSC data informed by the ICCs and design effects indicates that PSC is not just a simple sum up of individual characteristics. PSC is deeply rooted and shaped by the characteristics of collective bodies in an organisation, beyond the level of individuals. This finding aligns with the definition of culture and is consistent with studies conducted elsewhere. ${ }^{28} 52$ Interestingly, our results show that variations in 'patient engagement' and 'transfer and handoff' are more likely to be shaped by institutional differences rather than position differences. By contrast, variations in 'staffing and workloads', 'reporting of adverse events' and 'work commitment' are more likely to be shaped by position differences rather than institutional differences. The other components of PSC, including 'managerial response to patient safety risks', 'perceived management support', 'staff empowerment', 'defensive medical practice' and 'training' are sensitive to both position and institutional differences.

We found that 'staffing and workloads' is negatively correlated with 'reporting of adverse events' and 'work commitment', and it has no significant correlations with 'patient engagement', 'managerial response to patient safety risks', and 'transfer and handoff'. Interpretations of these results need to be cautious. It has been widely agreed that a shortage of workforce and excessive workloads are detrimental to patient safety. ${ }^{64} 65$ However, in a system where patients enjoy freedom to choose care providers, crowdedness (high workloads) can be 


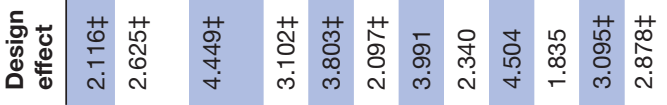

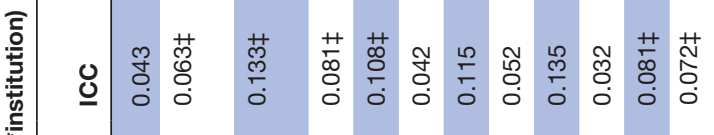

v

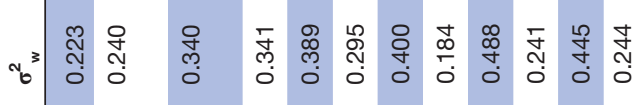

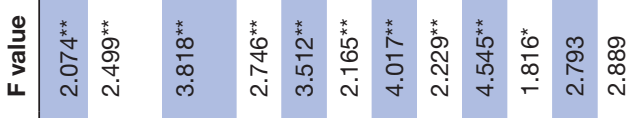

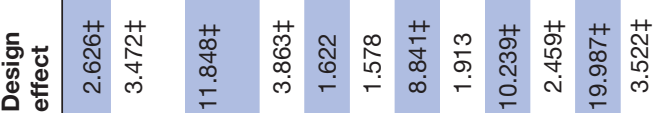

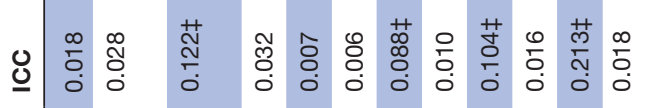

v

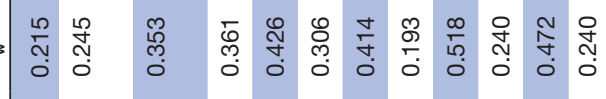

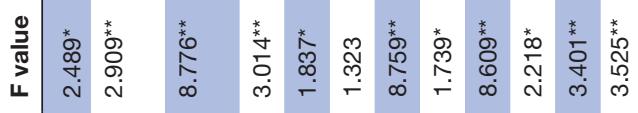

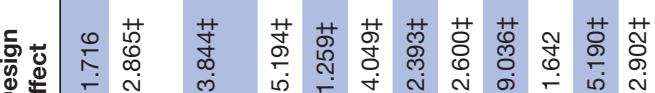

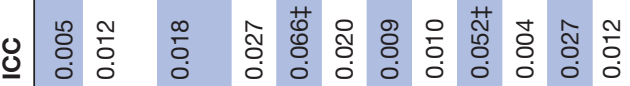

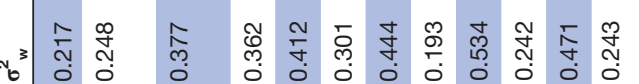

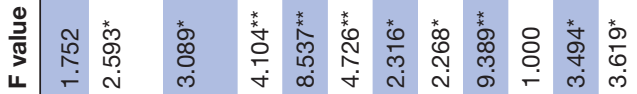




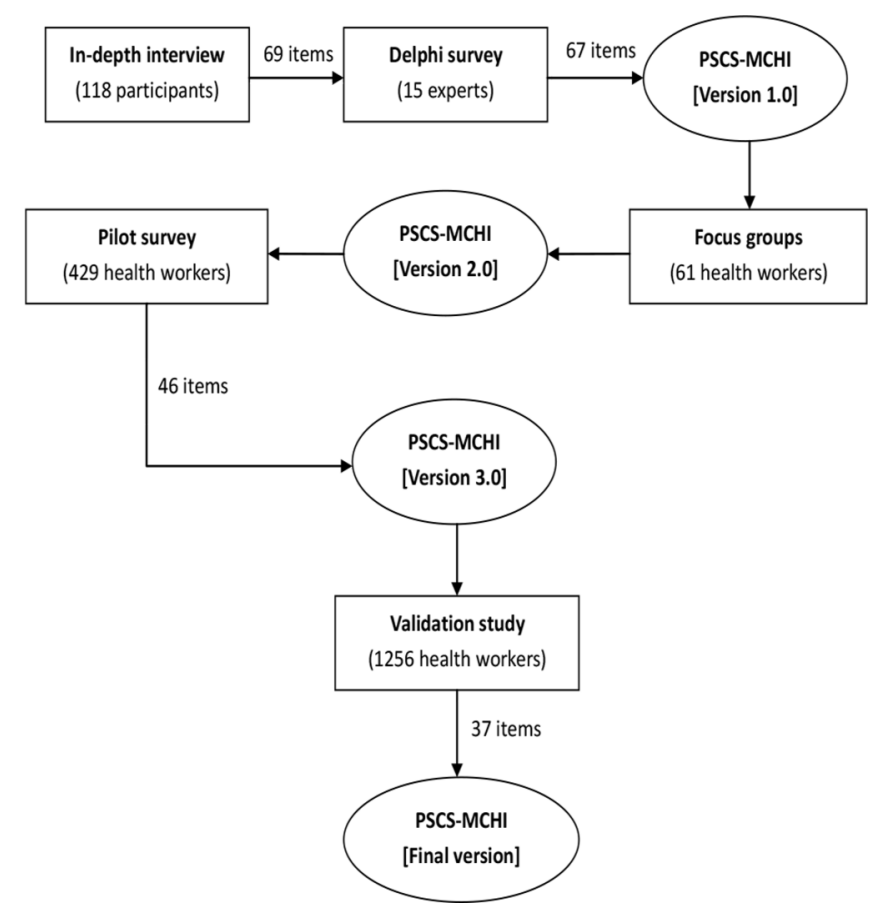

Figure 1 Development of patient safety culture survey for maternal and child health institutions (PSCS-MCHI).

a reflection of patient preference and perceived high quality of care. ${ }^{5166}$ In China, there is no 'safe workload' policy. Managers often encourage health workers to take on more workloads to demonstrate loyalty and commitment to the organisations. ${ }^{62}$ The hierarchical nature of the PSC data may also confound the inter-subscale correlation analyses based on data measured at the individual level. MCH institutions with higher patient loads are more likely to employ health workers with higher qualifications, ${ }^{67} 68$ increasing their prospect of nurturing a better PSC. ${ }^{62} 69$

\section{PSC in MCH institutions}

Although there is a lack of benchmarking criteria, this study revealed particular low scores in 'staffing and workloads', 'perceived management support' and 'defensive medical practice'. Indeed, understaffing and overloading is a common complaint in China's healthcare industry. ${ }^{27} 62$ Meanwhile, defensive medical practice is also prevalent and has attracted increasing criticism, damaging medical professionalism. ${ }^{70-72}$ It is important to notice that the shortage of perceived management support in the $\mathrm{MCH}$ setting often points to a lack of acknowledgement on the contributions of preventive care, poor communications, and prejudice to individuals who commit errors. Surprisingly, the respondents of this study gave relatively high ratings on patient safety and reported few events despite these low scores. Further studies are needed to better understand the situation of patient safety in $\mathrm{MCH}$ institutions.

While workforce development is important, more attention should be diverted to health promotion and preventive care in $\mathrm{MCH}$ settings. The lack of trust between patients and providers imposes a serious challenge to the development of PSC ${ }^{7374}$ and adopt of a non-punitive approach to medical errors. ${ }^{875}{ }^{76}$ Coordinated efforts of the society is needed to cope with this problem, involving all stakeholders including health workers, patients, health managers, policy makers and medical students. ${ }^{77-82}$

\section{Suggestions drawn from the findings}

There are several suggestions that can be drawn from the findings of this study. First, Staff empowerment is extracted as a component of PSC in this study and high involvement management has been proved to improve employees' well-being. ${ }^{83}$ It is necessary to make a priority of promoting frontline workers' engagement in decision-making processes, through creating a flat organisational structure, improving the decision-making capabilities of frontline workers, and ensuring them by policies and regulations. ${ }^{36-40}$ Second, considering that health service outcomes are produced by providers and customers together, patients should be encouraged to participate in all processes of healthcare decision making, which can be helpful to improve the relationship between providers and customers and thereby to reduce providers' defensive medical practice. Third, overloading is an outstanding problem in patient safety, especially in China's medical institutions. However, work commitment has been overemphasised to encourage health workers to bear overloaded work, which may harm their own health. ${ }^{84}$ It's time to establish a 'safe workload' policy in China and put both patients and health workers in a safer place.

\section{Limitations}

This study has several limitations. First, the study sample was not randomly selected and it was just undertaken in Zhejiang province. A national representative study will be needed to establish benchmarking criteria, which is essential for appropriate data interpretation. This limitation also results in that the findings in this study are context specific and caution should be taken when generalising these findings. Second, this paper focuses on introducing a tailored tool for $\mathrm{MCH}$ institutions (PSCS-MCHI), including its components and psychometric properties, as well as indicating that PSC in MCH institutions exists potential multilevel heterogeneities in individual level, positional level and institutional level. Further analyses and studies should be aimed to explore multilevel variables how to influence PSC of the organisation, such as gender, education, work experience and other personality traits in individual level, different groups in positional level, grade-ranking, scale and other organisational traits in institutional level. Third, although both patients and health workers were involved in developing the theoretical framework of the PSCS-MCHI, this questionnaire's objects are defined as health workers, since PSC is a kind of common value shared by members of an organisation. ${ }^{1011}$ However, considering that patient engagement is an important part of PSC, it should be necessary to make 
the PSCS-MCHI verified by patients or develop a specific subscale for patients in further studies. ${ }^{35}$

\section{CONCLUSION}

The PSCS-MCHI is a valid tool for assessing PSC in MCH settings. The scale comprises ten subscales, which have demonstrated a hierarchical structure of data. PSC in MCH settings is shaped by the characteristics of individuals, job positions and institutions. Multilevel modelling is advised for studies using the PSCS-MCHI.

\section{Author affiliations}

${ }^{1}$ Department of Obstetrics and Gynecology and Reproductive Medicine Center, Peking University Third Hospital, Beijing, China

${ }^{2}$ School of Public Health, Peking University, Beijing, China

${ }^{3}$ Women's Hospital, School of Medicine, Zhejiang University, Hangzhou, China

${ }^{4}$ School of Psychology and Public Health, La Trobe University, Bundoora, Victoria, Australia

${ }^{5}$ Second Outpatient Department, Peking University Third Hospital, Beijing, China

Acknowledgements The authors wish to acknowledge the contributions of the 14 $\mathrm{MCH}$ institutions, including the individuals who offered help and participated in the survey.

Contributors YYW led data analyses and writing of the manuscript. HH participated in data collection and data analyses. LQ coordinated data collection. CL supervised the research design, data analyses, interpretation of results and writing of the manuscript. As corresponding authors, YW and WL contributed equally in conceptualising the study. All authors contributed to writing and approved the final version of the manuscript.

Funding This study was funded by the China-US Center for Medical

Professionalism, Peking University Health Science Center.

Competing interests None declared.

Patient consent for publication Not required.

Ethics approval Peking University Third Hospital Medical Science Research Ethics Committee (IRB00006761-M2014040).

Provenance and peer review Not commissioned; externally peer reviewed.

Data availability statement Data are available upon reasonable request.

Open access This is an open access article distributed in accordance with the Creative Commons Attribution Non Commercial (CC BY-NC 4.0) license, which permits others to distribute, remix, adapt, build upon this work non-commercially, and license their derivative works on different terms, provided the original work is properly cited, appropriate credit is given, any changes made indicated, and the use is non-commercial. See: http://creativecommons.org/licenses/by-nc/4.0/.

\section{REFERENCES}

1. Jha AK, Larizgoitia I, Audera-Lopez C, et al. The global burden of unsafe medical care: Analytic modelling of observational studies. BMJ Qual Saf 2013;22:809-15.

2. Singh H, Schiff GD, Graber ML, et al. The global burden of diagnostic errors in primary care. BMJ Qual Saf 2017;26:484-94.

3. Sheldon T. Deaths from adverse events are halved in Dutch hospitals. BMJ 2013;347.

4. World Health Organization. Who patient safety curriculum guide for medical schools. Geneva: World Health Organization, 2009.

5. Sherman H, Castro G, Fletcher M, et al. Towards an international classification for patient safety: the conceptual framework. International Journal for Quality in Health Care 2009;21:2-8.

6. Runciman W, Hibbert P, Thomson R, et al. Towards an international classification for patient safety: key concepts and terms. International Journal for Quality in Health Care 2009;21:18-26.

7. Rodrigues SP, van Eck NJ, Waltman L, et al. Mapping patient safety: a large-scale literature review using bibliometric visualisation techniques. BMJ Open 2014;4:e004468

8. Institute of Medicine. To err is human: building a safer health system. Washington, DC: National Academics Press, 1999.
9. Jha AK, Prasopa-Plaizier N, Larizgoitia I, et al. Patient safety research: an overview of the global evidence. Quality and Safety in Health Care 2010;19:42-7.

10. Weaver SJ, Lubomksi LH, Wilson RF, et al. Promoting a culture of safety as a patient safety strategy: a systematic review. Ann Intern Med 2013;158:369-74.

11. Nieva VF, Sorra J. Safety culture assessment: a tool for improving patient safety in healthcare organizations. Quality and Safety in Health Care 2003;12:17ii-23.

12. DiCuccio $\mathrm{MH}$. The relationship between patient safety culture and patient outcomes. J Patient Saf 2015;11:135-42.

13. Chassin MR, Loeb JM. High-Reliability health care: getting there from here. Milbank Quarterly 2013;91:459-90.

14. Padgett J, Gossett K, Mayer R, et al. Improving patient safety through high reliability organizations. Qualitative Report 2017;22:410-25.

15. Sexton JB, Sharek PJ, Thomas EJ, et al. Exposure to leadership WalkRounds in neonatal intensive care units is associated with a better patient safety culture and less caregiver burnout. BMJ Qual Saf 2014;23:814-22.

16. Zwijnenberg NC, Hendriks M, Hoogervorst-Schilp J, et al. Healthcare professionals' views on feedback of a patient safety culture assessment. BMC Health Serv Res 2016;16.

17. Lee S-H, Phan PH, Dorman T, et al. Handoffs, safety culture, and practices: evidence from the hospital survey on patient safety culture. BMC Health Serv Res 2016;16.

18. Bishop AC, Boyle TA. The role of safety culture in influencing provider perceptions of patient safety. J Patient Saf 2016;12:204-9.

19. Bates DW, Larizgoitia I, Prasopa-Plaizier N, et al. Global priorities for patient safety research. BMJ 2009;338:b1775.

20. Xuanyue M, Yanli N, Hao C, et al. Literature review regarding patient safety culture. J Evid Based Med 2013;6:43-9.

21. Sammer CE, Lykens $\mathrm{K}$, Singh KP, et al. What is patient safety culture? A review of the literature. J Nurs Scholarsh 2010;42:156-65.

22. Wagner C, Smits M, Sorra J, et al. Assessing patient safety culture in hospitals across countries. Int J Qual Health Care 2013;25:213-21.

23. Meddings J, Reichert H, Greene MT, et al. Evaluation of the association between hospital survey on patient safety culture (HSOPS) measures and catheter-associated infections: results of two national Collaboratives. BMJ Qual Saf 2017;26:226-35.

24. Sexton JB, Helmreich RL, Neilands TB, et al. The safety attitudes questionnaire: psychometric properties, benchmarking data, and emerging research. BMC Health Serv Res 2006;6:44.

25. Parker D. Managing risk in healthcare: understanding your safety culture using the Manchester patient safety framework (MaPSaF). $J$ Nurs Manag 2009;17:218-22.

26. Nie $\mathrm{Y}$, Mao X, Cui $\mathrm{H}$, et al. Hospital survey on patient safety culture in China. BMC Health Serv Res 2013;13:228.

27. Jia PL, Zhang LH, Zhang MM, et al. Safety culture in a pharmacy setting using a pharmacy survey on patient safety culture: a crosssectional study in China. BMJ Open 2014;4:e004904.

28. Zhu J, Li L, Zhao H, et al. Development of a patient safety climate survey for Chinese hospitals: cross-national adaptation and psychometric evaluation. BMJ Qual Saf 2014;23:847-56.

29. Zhou P, Bundorf MK, Gu J, et al. Survey on patient safety climate in public hospitals in China. BMC Health Serv Res 2015;15:53.

30. Li Y, Zhao X, Zhang X, et al. Validation study of the safety attitudes questionnaire (SAQ) in public hospitals of Heilongjiang Province, China. PLoS One 2017;12:e0179486.

31. Liu Y, Kalisch BJ, Zhang L, et al. Perception of safety culture by nurses in hospitals in China. J Nurs Care Qual 2009;24:63-8.

32. Ginsburg LR, Tregunno D, Norton PG, et al. 'Not another safety culture survey': using the Canadian patient safety climate survey (Can-PSCS) to measure provider perceptions of PSC across health settings. BMJ Qual Saf 2014;23:162-70.

33. Verbakel NJ, Zwart DLM, Langelaan M, et al. Measuring safety culture in Dutch primary care: psychometric characteristics of the SCOPE-PC questionnaire. BMC Health Serv Res 2013;13:354.

34. Tomazoni A, Rocha PK, Souza Sde, de Souza S, et al. Patient safety culture at neonatal intensive care units: perspectives of the nursing and medical team. Rev Lat Am Enfermagem 2014;22:755-63.

35. Cox ED, Carayon P, Hansen KW, et al. Parent perceptions of children's Hospital safety climate. BMJ Qual Saf 2013;22:664-71.

36. Hammer A, Ernstmann N, Ommen O, et al. Psychometric properties of the hospital survey on patient safety culture for hospital management (HSOPS_M). BMC Health Serv Res 2011;11:165.

37. Health - United Nations Sustainable Development, 2017. Available: http://www.un.org/sustainabledevelopment/health/

38. Hosseinpoor AR, Bergen N, Schlotheuber A. Promoting health equity: who health inequality monitoring at global and national levels. Glob Health Action 2015;8:29034. 
39. Valentine NB, Koller TS, Hosseinpoor AR. Monitoring health determinants with an equity focus: a key role in addressing social determinants, universal health coverage, and advancing the 2030 sustainable development agenda. Glob Health Action 2016:9:34247.

40. National Health and Family Planning Commission. National health statistics Yearbook 2016. Beijing: Peking Union Medical College Press, 2017.

41. Guidance on standardized organizational construction and management of maternal and child health service institutions National Health and Family Planning Commission of the People's Republic of China 2016. Available: http://www.nhfpc.gov.cn/fys/ s3581/201512/a0dcaf1f20624769a9a3b2dafa0280ab.shtml

42. Guo Y, Bai J, Na H. The history of China's maternal and child health care development. Seminars in Fetal and Neonatal Medicine 2015;20:309-14.

43. PMNCH. WHO, World Bank and AHPSR. Success Factors for Women's and Children's Health Policy and programme highlights from 10 fast-track countries. Geneva: WHO, 2014.

44. National Health Commission of the People's Republic of China China's foreign assistances: 100 programmes on women and children's health in five years. Available: http://www.nhfpc.gov.cn/ zhuz/xwfb/201805/9c8bf79272c14acaa427970ff0b5d00f.shtml

45. Tang K, Li Z, Li W, et al. China's silk road and global health. The Lancet 2017;390:2595-601.

46. Tambo Eet al. China-Africa health development initiatives: benefits and implications for shaping innovative and evidence-informed National health policies and programs in sub-Saharan African countries. Int. J. MCH AIDS 2016;5:119-33.

47. Hessels AJ, Murray M, Cohen B, et al. Patient safety culture survey in pediatric complex care settings. J Patient Saf 2017:1 (published Online First: 2017/04/19).

48. Ribeliene J, Blazeviciene A, Nadisauskiene RJ, et al. Patient safety culture in obstetrics and gynecology and neonatology units: the nurses' and the midwives' opinion. J Matern Fetal Neonatal Med 2019;32:3244-50.

49. National Health and Family Planning Commission of the People's Republic of China. The regulation of maternal and child health institutions, 2006. Available: http://www.nhfpc.gov.cn/zwgk/wtwj/ 201304/5aac934c79714c02b6acb688b16554b1.shtm

50. Charmaz K. Constructing grounded theory. 2nd edn. London, Thousand Oaks, Calif: Calif, Sage, 2014

51. Wang $\mathrm{Y}$, Liu W, Shi H, et al. Measuring patient safety culture in maternal and child health institutions in China: a qualitative study. BMJ Open 2017;7:e015458.

52. Sorra JS, Dyer N. Multilevel psychometric properties of the AHRQ Hospital survey on patient safety culture. BMC Health Serv Res 2010;10:199.

53. DeVellis RF. Scale development: theory and applications. 4th edn Los Angeles: Sage, 2017.

54. Matsubara S, Hagihara A, Nobutomo K. Development of a patient safety climate scale in Japan. Int J Q Health Care 2008;20:211-20.

55. Kelloway EK. Using mPLUS for structural equation modeling: a researcher's quide. 2nd edn. Los Angeles: Sage, 2015.

56. Brown TA. Confirmatory factor analysis for applied research. 2nd edn New York, London: The Guilford Press, 2015.

57. Byrne BM. Structural equation modeling with Amos: basic concepts, applications, and programming. 3rd edn. New York: Routledge, Taylor \& Francis Group, 2016.

58. Chen I-C, $\mathrm{Li} \mathrm{H}-\mathrm{H}$. Measuring patient safety culture in Taiwan using the hospital survey on patient safety culture (HSOPSC). BMC Health Serv Res 2010;10:152.

59. Heck RH, Thomas SL. An introduction to multilevel modeling techniques. 2nd edn. New York: Routledge, 2009.

60. Wang J, Xie H, Fischer JH. Multilevel models: applications using SAS. Berlin; Boston Beijing: De Gruyter, Higher Education Press, 2012.

61. Metcalf PA, Scragg RKR, Stewart AW, et al. Design effects associated with dietary nutrient intakes from a clustered design of 1 to 14-year-old children. Eur J Clin Nutr 2007:61:1064-71.

62. Liu C, Liu W, Wang Y, et al. Patient safety culture in China: a case study in an outpatient setting in Beijing. BMJ Qual Saf 2014;23:556-64.
63. Liu C, Bartram T, Casimir G, et al. The link between participation in management decision-making and quality of patient care as perceived by Chinese doctors. Public Management Review 2015:17:1425-43.

64. Smeds Alenius L, Tishelman C, Runesdotter S, et al. Staffing and resource adequacy strongly related to RNs' assessment of patient safety: a national study of RNs working in acute-care hospitals in Sweden. BMJ Qual Saf 2014;23:242-9.

65. Shekelle PG. Nurse-patient ratios as a patient safety strategy: a systematic review. Ann Intern Med 2013;158:404-9.

66. Zhou Z, Wang C, Yang $\mathrm{H}$, et al. Health-Related quality of life and preferred health-seeking institutions among rural elderly individuals with and without chronic conditions: a populationbased study in Guangdong Province, China. Biomed Res Int 2014;2014:192376-10.

67. National Center for Women and Children's Health, China CDC. Annual report of health resources and performances in maternal and child health institutions (2015), 2016. Available: http://www. myendnoteweb.com/EndNoteWeb.html?cat=myrefs [Accessed 12 Sep 2017].

68. Ren Z, Song P, Theodoratou E, et al. China's human resources for maternal and child health: a national sampling survey. BMC Health Serv Res 2015;15:561.

69. Chen J, Xu J, Zhang C, et al. Medical professionalism among clinical physicians in two tertiary hospitals, China. Soc Sci Med 2013;96:290-6

70. He AJ. The doctor-patient relationship, defensive medicine and overprescription in Chinese public hospitals: evidence from a crosssectional survey in Shenzhen City. Soc Sci Med 2014;123:64-71.

71. Panella M, Rinaldi C, Leigheb F, et al. Prevalence and costs of defensive medicine: a national survey of Italian physicians. J Health Serv Res Policy 2017;22:211-7.

72. Küçük M. Defensive medicine among obstetricians and gynaecologists in turkey. J Obstet Gynaecol 2018;38:200-5.

73. Nie JB, Cheng Y, Zou X, et al. The vicious circle of patientphysician mistrust in China: health professionals' perspectives, institutional conflict of interest, and building trust through medical professionalism. Dev World Bioeth 2018;18:26-36.

74. Zhang L, Stone TE, Zhang J. Understanding the rise of Yinao in China: a commentary on the little known phenomenon of healthcare violence. Nurs Health Sci 2017;19:183-7.

75. Reason J. Beyond the organisational accident: the need for "error wisdom" on the frontline. Qual Saf Health Care 2004;13(suppl_2):ii28-33.

76. Reason J. Safety in the operating theatre - Part 2: human error and organisational failure. Qual Saf Health Care 2005;14:56-60.

77. Abbott JF, Pradhan A, Buery-Joyner S, et al. To the point: integrating patient safety education into the obstetrics and gynecology undergraduate curriculum. J Patient Saf 2016. doi:10.1097/ PTS.0000000000000250. [Epub ahead of print: 26 Jul 2016].

78. World Health Organization. Who patient safety. patient safety curriculum guide: multi-professional edition. Geneva: World Health Organization, 2011.

79. Fox MD, Bump GM, Butler GA, et al. Making residents part of the safety culture: improving error reporting and reducing harms. $J$ Patient Saf 2017. doi:10.1097/PTS.0000000000000344. [Epub ahead of print: 30 Jan 2017].

80. Holmström A-R, Airaksinen M, Weiss M, et al. National and local medication error reporting systems: a survey of practices in 16 countries. J Patient Saf 2012;8:165-76.

81. Howell A-M, Burns EM, Hull L, et al. International recommendations for national patient safety incident reporting systems: an expert Delphi consensus-building process. BMJ Qual Saf 2017;26:150-63.

82. Flemons $W, M c R a e ~ G$. Reporting, learning and the culture of safety. Healthc Q 2012;15:12-17.

83. Böckerman P, Bryson A, Ilmakunnas P. Does high involvement management improve worker wellbeing? J Econ Behav Organ 2012;84:660-80.

84. Gates M, Wingert A, Featherstone R, et al. Impact of fatigue and insufficient sleep on physician and patient outcomes: a systematic review. BMJ Open 2018;8:e021967. 